\title{
Desempenho Produtivo de Vacas 5/8 Holando/Zebu Alimentadas com Diferentes Cultivares de Palma Forrageira (Opuntia e Nopalea) ${ }^{1}$
}

\author{
Djalma Cordeiro dos Santos ${ }^{2}$, Mércia Virginia Ferrreira dos Santos ${ }^{3}$, Iderval Farias ${ }^{2}$, \\ Flávio Marcos Dias ${ }^{2}$, Mário de Andrade Lira ${ }^{2}$
}

\begin{abstract}
RESUMO - Foi estudado o efeito de diferentes cultivares de palma forrageira sobre o desempenho produtivo de vacas mestiças holando/zebu. O delineamento experimental foi de ensaios alternativos, obedecendo a distribuição de quadrado latino, contendo três quadrados, com três períodos de 28 dias cada. Os tratamentos foram constituídos pelas cultivares de palma forrageira redonda, gigante e miúda. De modo geral, foram observadas pequenas variações na composição química dos cultivares de palma. Não foi observada diferença significativa quanto ao consumo de palma in natura, consumo de restolho de milho e consumo de matéria seca, entre os animais alimentados com as diferentes cultivares de palma, sendo de 54,21; 7,91; e 9,04 kg/dia, respectivamente. Também não foi observada diferença para as variáveis leite produzido, leite a $4 \%$ de gordura e relação de consumo de matéria seca para leite produzido. Os dados sugerem que vacas leiteiras mestiças podem ser alimentadas com diferentes cultivares de palma forrageira, sem comprometimento do desempenho produtivo das mesmas.
\end{abstract}

Palavras-chave: composição química, cultivares, produção de leite

\section{Productive Performance of 5/8 Holstein/Zebu Dairy Cows Fed Different Cactus Forage Cultivars (Opuntia and Nopalea)}

\begin{abstract}
The effect of different cactus forage cultivars upon the productive performance of 5/8 Holstein/Zebu dairy cows was studied. A latin square design was used in an alternative assay distribution, with three squares and three periods of 28 day each. The treatments were constituted of the cactus cultivars "Redonda", "Gigante" and "Miúda". A few variations in the chemical composition were observed among cactus cultivars. No differences were observed as for fresh cactus forage and corn stalks intake, and dry matter intake, among the animal fed different cactus cultivars, with 54.21, 7.91, and $9.04 \mathrm{~kg} /$ day, respectively. Also, no difference was observed for milk yield, $4 \%$ corrected fat milk yield and dry matter intake per milk yield. The data suggested that crossbred dairy cows could be fed with different cactus forage cultivars, without reducing their productive performance.
\end{abstract}

Key Words: chemical composition, cultivars, milk production

\section{Introdução}

A palma forrageira vem se constituindo, nas duas últimas décadas, uma das principais forrageiras cultivadas na bacia leiteira do Estado de Pernambuco, bem como em grande parte da região semi-árida do Nordeste. CHAGAS (1992), em levantamento realizado no Agreste de Pernambuco, observou que, em propriedades variando de 5 a 50 hectares, a palma é cultivada em $32 \%$ da área. Afirma-se existir no Nordeste do Brasil cerca de 400 mil hectares de palma forrageira, entretanto, acredita-se que exista atualmente 500 mil hectares no Nordeste e 100 mil em Pernambuco. Segundo SANTOS et al. (1997), esta cactácea constitui um alimento volumoso suculento de grande importância para os rebanhos, notadamente nos períodos de estiagens prolongadas, pois, além de fornecer um alimento verde, supre grande parte das necessidades de água dos animais. Segundo COSTA et al. (1973), a importância da utilização da palma na alimentação animal é principalmente por sua riqueza em água e mucilagem, bem como pelo elevado coeficiente de digestibilidade da matéria seca e alta produtividade. Vale ressaltar a alta produção de matéria seca da palma forrageira em secas prolongadas, em relação a outras forrageiras, sendo uma das principais opções disponíveis em determinadas situações.

Os resultados de pesquisa até o momento mostram a necessidade de se avaliar a palma forrageira para melhorar sua utilização. A palma apresenta alguns aspectos que podem ser considerados limitantes,

\footnotetext{
1 Projeto financiado IPA/EMBRAPA.

2 Pesquisador do IPA. E.mail: mlira@hotlink.com.br

3 Professor da UFRPE - Rua Dom Manoel de Medeiros, s/n, Dois Irmãos. E.mail: rmsantos@elogica.com.br
} 
como deficiência de proteína bruta (SANTOS et al., 1992), que se situa no limite inferior às necessidades dos microrganismos do rúmen (VAN SOEST, 1994), baixo nível de ingestão de matéria seca e, também, reduzida quantidade de fibra, com 26,7 e $21,5 \%$ de fibra em detergente neutro e fibra em detergente ácido, respectivamente (CUNHA, 1996).

SANTANA et al. (1972), trabalhando com vacas holandesas, não encontraram diferença significativa quanto à produção de leite e ao teor de gordura do leite entre os animais alimentados com silagem de milho e palma, porém os mesmos apresentaram variação de peso vivo de $437,-456$ e $-230 \mathrm{~g} /$ dia, quando receberam silagem de milho, palma, e palma mais $10 \mathrm{~kg} /$ dia de silagem de milho, respectivamente.

Tradicionalmente, são utilizadas no Estado de Pernambuco três cultivares de palma forrageira, redonda, miúda e gigante, as quais apresentam algumas diferenças quanto ao valor nutritivo (SANTOS et al., 1997). Nesse sentido, SANTOS et al. (1992) observaram diferença não-significativa para produção de leite de vacas holandesas alimentadas com diferentes cultivares. Entretanto, os animais alimentados com a cultivar miúda apresentaram maior consumo de matéria seca e menor perda de peso vivo, em relação aos animais alimentados com as cultivares redonda e gigante.

Animais mestiços são utilizados em grande número de fazendas leiteiras, devido à maior rusticidade desses animais e adaptação às condições de semiárido, em relação aos animais puros. Assim, o objetivo deste trabalho foi avaliar o desempenho de vacas mestiças 5/8 holando-zebu, alimentadas com diferentes cultivares de palma forrageira, associadas com silagem de restolho de milho doce.

\section{Material e Métodos}

O experimento foi conduzido na Estação Experimental de Arcoverde, da Empresa Pernambucana de Pesquisa Agropecuária (IPA), no período de 29 de novembro de 1991 a 2 de março de 1992 . Foram utilizadas nove vacas mestiças 5/8 holando/zebu.

O delineamento experimental utilizado foi o de ensaios alternativos, obedecendo a distribuição de quadrado latino, contendo três quadrados, com três períodos de 28 dias cada, sendo sete dias de adaptação, por ocasião da mudança de tratamento, e 21 dias de período experimental. Todo o experimento foi realizado na época considerada seca na região.

No início do trabalho, as vacas estavam com produção média de leite de $4,8 \mathrm{~kg} / \mathrm{dia}$ e se encontravam em estádio de lactação variável de 21 a 95 dias. As ordenhas foram realizadas diariamente, às 5 e $15 \mathrm{~h}$, com bezerro ao pé, deixando-se o leite de uma teta para o bezerro. A teta a ser deixada para o bezerro foi alternada a cada dia.

Os tratamentos experimentais foram as diferentes cultivares de palma forrageira, conforme descrito a seguir: T1- palma cv. redonda; T2- palma cv. gigante e T3 - palma cv. miúda.

A palma utilizada neste experimento, com aproximadamente 4 anos, foi colhida manualmente na altura do artículo primário. Após o corte manual e pesagem, a palma forrageira era fornecida aos animais.

A cada animal foi destinada uma baia dotada de comedouro e bebedouro. Após a primeira ordenha, as vacas permaneceram nos currais, em baias individuais, até as $18 \mathrm{~h}$, sendo em seguida levadas para local coletivo sem qualquer alimentação. Os animais tinham acesso à farinha de osso e sais minerais três vezes ao dia.

A alimentação foi baseada no fornecimento de $2,5 \mathrm{~kg}$ de MS/100 kg PV, sendo constituída de palma forrageira, segundo os tratamentos experimentais, associada à silagem de restolho de milho doce e concentrado comercial. Pela manhã, foi fornecida a silagem e à tarde, a palma, obedecendo uma proporção em matéria seca de aproximadamente $25 \%$ de silagem e $75 \%$ de palma. O fornecimento do concentrado foi realizado por ocasião da primeira ordenha, sendo fornecido $1 \mathrm{~kg}$ de concentrado a cada animal, o qual apresentava $90 \%$ de MS e $24 \%$ de PB, e era composto de farelo de trigo e soja, bem como $30 \mathrm{~g}$ de uréia. Após o oferecimento dos alimentos, o material não-consumido foi pesado. A água foi fornecida à vontade aos animais.

As produções individuais de leite foram pesadas por ocasião das duas ordenhas, realizadas em intervalos de aproximadamente 12 horas. Foram coletadas amostras de leite de duas ordenhas consecutivas, uma vez por semana, para determinação do teor de gordura, extrato seco e densidade do leite, conforme metodologia de COELHO e ROCHA (1991). Semanalmente foram coletadas amostras de fezes direto no reto, para determinação da matéria seca das mesmas.

Amostras dos alimentos utilizados foram coletadas semanalmente e misturadas quatro amostras semanais, de modo a se obter amostra composta em cada período experimental. As amostras compostas foram enviadas ao laboratório de Nutrição Animal da Em- 
14 Rev. bras. zootec.

presa Pernambucana de Pesquisa Agropecuária, para que fossem realizadas as análises de matéria seca, proteína bruta, fibra bruta, cálcio e fósforo, segundo SILVA (1990).

Os tratamentos experimentais foram comparados pelo teste Tukey, a 5\% de probabilidade.

\section{Resultados e Discussão}

Os valores percentuais de matéria seca, proteína bruta, cálcio e fósforo dos alimentos utilizados no experimento são apresentados na Tabela 1. De maneira geral, foram observadas pequenas diferenças na porcentagem de matéria seca e proteína bruta das diferentes cultivares de palma. Para porcentagem de matéria seca, não foi observada diferença significativa entre as cultivares, sendo de 11,$0 ; 10,6$; e 12,0 para redonda, gigante e miúda, respectivamente, valores inferiores aos encontrados por MATTOS (2000). A palma forrageira apresenta baixo conteúdo de matéria seca, quando comparada à maioria das forrageiras. Este aspecto compromete o atendimento das necessidades de matéria seca dos animais que recebem exclusivamente palma e, provavelmente, a elevada umidade limita o consumo pelo controle físico, por meio do enchimento do rúmen.

Por outro lado, vale ressaltar que a elevada umidade observada na palma forrageira, independente da cultivar, é uma característica importante, tratando-se de região semi-árida, no atendimento de grande parte das necessidades de água dos animais, principalmente no período seco do ano.

A tendência de maior porcentagem de matéria seca observada para a cultivar miúda concorda os resultados obtidos por SANTOS et al. (1990), trabalhando com a mesma cultivar, e é de importância considerando a limitação da palma no atendimento das necessidades de matéria seca do animal.

A porcentagem média de proteína bruta da palma foi superior à observada por LIMA et al. (1985), FARIAS et al. (1989) e SANTOS et al. (1997) e semelhante à encontrada por GERMANO et al. (1991). Os valores de proteína bruta mais elevados que os observados na literatura, provavelmente, estão associados à colheita de um material de melhor qualidade, devido a um manejo mais racional que vem sendo dado a essa cultura, como adubação e altura de corte adequada.

Os valores de fibra bruta obtidos foram de 7,97; 9,39 ; e $8,92 \%$ para as palmas redonda, gigante, miúda, respectivamente, os quais não diferiram significativamente entre si. O teor de fibra bruta da silagem de restolho de milho foi de 33,29\%. Os valores de fibra bruta obtidos para palma são próximos aos encontrados por SANTOS et al. (1998). Notam-se baixos valores de fibra, quando comparados aos níveis recomendados pelo NATIONAL RESEARCH COUNCIL - NRC (1988), que é de no mínimo $17 \%$ de FB e $28 \%$ de FDN na dieta, sendo que $75 \%$ da FDN deve ser proveniente do volumoso. A quantidade de fibra pode influenciar o bom funcionamento de rúmen e provavelmente, contribui para as diarréias (SANTANA et al., 1972; SANTOS et al., 1990) observadas em animais alimentados exclusivamente com palma ou elevada participação de palma na ração. Por outro lado, o nível adequado de fibra é necessário, principalmente nas vacas em lactação, pois tal componente interferirá, decisivamente, no teor de gordura do leite (MERTES, 1992). Nesse sentido, MATTOS (2000), trabalhando com diferentes fontes de fibra associadas à palma, não observou diferenças entre os animais quanto à produção e composição do leite, sendo que, ao se considerar a

Tabela 1 - Composição química dos alimentos, Arcoverde-PE Table 1 - Chemical composition of feeds, Arcoverde-PE

\begin{tabular}{|c|c|c|c|c|}
\hline \multirow[t]{2}{*}{$\begin{array}{l}\text { Alimento } \\
\text { Feed }\end{array}$} & \multirow[b]{2}{*}{$\begin{array}{l}\text { Matéria seca } \\
\text { Dry matter }\end{array}$} & \multicolumn{3}{|c|}{$\begin{array}{l}\text { \% Matéria seca } \\
\% \text { Dry matter }\end{array}$} \\
\hline & & $\begin{array}{l}\text { Proteína bruta } \\
\text { Crude protein }\end{array}$ & $\begin{array}{l}\text { Cálcio } \\
\text { Calcium }\end{array}$ & $\begin{array}{c}\text { Fosfóro } \\
\text { Phosphorus }\end{array}$ \\
\hline Palma cv. Redonda & $11,00^{\mathrm{b}}$ & $5,93^{\mathrm{a}}$ & $1,88^{\mathrm{ab}}$ & 0,08 \\
\hline $\begin{array}{l}\text { Cactaceae cv. Redonda } \\
\text { Palma cv. Gigante } \\
\text { Cactaceae }\end{array}$ & $10,63^{b}$ & $6,32^{\mathrm{a}}$ & $2,31^{\mathrm{ab}}$ & 0,11 \\
\hline $\begin{array}{l}\text { Palma cv. Miúda } \\
\text { Cactaceae cv.Miúda }\end{array}$ & $11,96^{\mathrm{b}}$ & $6,28^{a}$ & $3,88^{\mathrm{a}}$ & 0,11 \\
\hline $\begin{array}{l}\text { Silagem de restolho de milho doce } \\
\text { Corn sweet silage }\end{array}$ & $25,60^{\mathrm{a}}$ & $6,16^{\mathrm{a}}$ & $0,48^{\mathrm{b}}$ & 0,05 \\
\hline
\end{tabular}


melhor relação custo/benefício, a utilização de bagaço in natura foi a mais recomendada.

Para as cultivares de palma, foram observados valores médios para porcentagem de cálcio e fósforo de 2,69 e 0,10\%, respectivamente. Estes valores estão acima da exigência de cálcio estabelecida pelo NRC (1988), para vacas em lactação e não atendendo exigência de fósforo e a relação $2: 1$ de cálcio e fósforo recomendada para bovinos. Além desses nutrientes, de maneira geral, a palma apresenta elevado conteúdo de minerais (MATTER, 1986).

O consumo de palma forrageira in natura, silagem e matéria seca das vacas alimentadas com as diferentes cultivares de palma é apresentado na Tabela 2 . $\mathrm{O}$ consumo de palma in natura variou de 53,13 a $55,87 / \mathrm{vaca} / \mathrm{dia}$, valores inferiores ao consumo médio obtido por SANTOS et al. (1998), trabalhando na mesma região. Não foi observada diferença significativa para as variáveis consumo de palma in natura e silagem, consumo de MS de silagem, consumo de MS/100 kg PV, bem como para consumo total de matéria seca entre os animais alimentados com as diferentes cultivares de palma forrageira.

Os cultivares de palma não influenciaram significativamente $(\mathrm{P}>0,05)$ o consumo total de matéria seca. Estes dados são justificados pelo fato de não ter havido diferenças $(P>0,05)$ na ingestão de silagem e concentrado. Os animais alimentados com a cultivar miúda apresentaram maior consumo de MS de palma $(\mathrm{P}<0,05)$, em relação aos alimentados com as cultivares redonda e gigante, o que está provavelmente associado à maior porcentagem de matéria seca apresentada por aquela cultivar (Tabela 1). Os resultados de consumo obtidos neste trabalho diferem dos obtidos por SANTOS et al. (1990), que encontraram maiores valores de consumo de palma in natura e silagem para os animais alimentados com a cultivar miúda, tendo estes autores trabalhado com animais da raça holandesa, que provavelmente apresentam maior capacidade digestiva que animais mestiços.

Vale ressaltar as variações de peso observadas neste experimento, - 0,323, -111 e $0,164 \mathrm{~g} / \mathrm{vaca} / \mathrm{dia}$ para os animais alimentados com palma redonda, gigante e miúda, respectivamente. A palma forrageira cv. miúda apresenta alta palatabilidade, o que está associado ao elevado nível de carboidratos solúveis, em relação às cultivares redonda e gigante (SANTOS et al., 1992), e provavelmente contribuiu para a melhor variação de peso vivo observada. A variação de peso vivo dos animais observada foi melhor que a observada por SANTANA et al. (1972) e SANTOS et al. (1990), indicando que no presente trabalho ocorreu melhor atendimento das necessidades dos animais. Entretanto, para a obtenção de produções de leite em quantidade, com bom desempenho animal, existe a necessidade de balanço de nutrientes na dieta e as perdas de peso ocorridas poderiam ser convertidas em maiores produções de leite.

Pode ser observado que o consumo de matéria seca está dentro do limite de 2,0 a 3,0 kg de MS/100 kg

Tabela 2 - Consumo de palma, silagem e concentrado in natura de vacas alimentadas com palma diferentes cultivares de palma, Arcoverde-PE

Table 2 - Intake of cactaceae, silage and concentrate fresh of cows fed cactaceae cultivar, Arcoverde-PE

\begin{tabular}{|c|c|c|c|c|}
\hline \multirow[t]{2}{*}{$\begin{array}{l}\text { Variáveis } \\
\text { Variables }\end{array}$} & \multicolumn{3}{|c|}{$\begin{array}{l}\text { Cultivares de palma } \\
\text { Cultivars of cactaceae }\end{array}$} & \multirow[b]{2}{*}{$\begin{array}{c}\text { Média } \\
\text { Mean }\end{array}$} \\
\hline & Redonda & Gigante & Miúda & \\
\hline $\begin{array}{l}\text { Consumo de palma in natura }(\mathrm{kg} / \mathrm{dia}) \\
\text { Intake of cactaceae }(\mathrm{kg} / \text { day) }\end{array}$ & $53,64^{\mathrm{a}}$ & $53,13^{\mathrm{a}}$ & $55,87^{\mathrm{a}}$ & 54,21 \\
\hline $\begin{array}{l}\text { Consumo de silagem }(\mathrm{kg} / \mathrm{dia}) \\
\text { Intake of silage }(\mathrm{kg} / \text { day })\end{array}$ & $8,16^{\mathrm{a}}$ & $7,97^{\mathrm{a}}$ & $7,60^{\mathrm{a}}$ & 7,91 \\
\hline $\begin{array}{l}\text { Consumo de MS de palma }(\mathrm{kg} / \mathrm{dia}) \\
\text { Intake of DM of cactaceae }(\mathrm{kg} / \text { day })\end{array}$ & $5,90^{\mathrm{a}}$ & $5,65^{\mathrm{b}}$ & $6,75^{\mathrm{a}}$ & 6,10 \\
\hline $\begin{array}{l}\text { Consumo de MS de silagem (kg/dia) } \\
\text { Intake of DM of silage ( } \mathrm{kg} / \text { day })\end{array}$ & $2,09^{\mathrm{a}}$ & $2,07^{\mathrm{a}}$ & $1,95^{\mathrm{a}}$ & 1,95 \\
\hline $\begin{array}{l}\text { Consumo de MS } / 100 \mathrm{~kg} \mathrm{PV} \\
\text { Intake of DM /100 kg of weight body }\end{array}$ & $2,27^{\mathrm{a}}$ & $2,23^{\mathrm{a}}$ & $2,35^{\mathrm{a}}$ & 2,04 \\
\hline $\begin{array}{l}\text { Consumo de MS (kg/dia) } \\
\text { Intake of DM ( } \mathrm{kg} / \text { day })\end{array}$ & $8,89^{\mathrm{a}}$ & $8,61^{\mathrm{a}}$ & $9,60^{\mathrm{a}}$ & $9,04^{\mathrm{a}}$ \\
\hline
\end{tabular}

Médias seguidas da mesma letra, na linha, não diferem pelo teste Tukey, a 5\% de probabilidade.

Means within a row, followed by same letter, did not differ $(P<.05)$ by Tukey test. 
de PV, recomendado pelo NRC (1988). Vale ressaltar que, neste experimento, utilizaram-se animais mestiços, com menor capacidade digestiva, em relação aos animais puros utilizados por SANTOS et al. (1990).

Por outro lado, o consumo de matéria seca observado está abaixo do encontrado por MATTOS (2000), trabalhando com vacas mestiças, o que pode estar associado à diferença de proporção de palma (38\%) e silagem na ração $(37,8 \%)$.

A produção de leite in natura, corrigido a $4 \%$ de gordura, a relação consumo de matéria seca e leite produzido, a porcentagem de gordura do leite, densidade e extrato seco do leite das vacas alimentadas com as diferentes cultivares de palma são apresentados na Tabela 3. Foi observada diferença significativa entre os tratamentos experimentais apenas para a variável percentagem de gordura do leite. A produção de leite observada foi inferior à encontrada por MATTOS (2000), trabalhando com o mesmo tipo de animal, o que, provavelmente, está relacionado ao fato de que no referido trabalho ocorreu adequado balanceamento de nutrientes fornecidos, sendo a palma utilizada na proporção de $38 \%$ e associada a $38 \%$ de silagem, $23 \%$ de concentrado e $1 \%$ de uréia. Além disso, no referido trabalho foi fornecida uma mistura com os alimentos, evidenciando a importância da sincronização de energia e proteína (PROPI e McLENNAN, 1995) para melhor aproveitamento dos nutrientes e, conseqüentemente, desempenho animal.

Os valores de gordura do leite foram superiores aos teores médios obtidos por SANTANA et al. (1972) e SANTOS et al. (1990) de 3,20 e 3,14, respectivamente, o que pode estar associado ao fato desses autores terem trabalhando com animais puros. MATTOS (2000) encontrou valor médio de 3,91\%, próximo aos obtidos neste trabalho.

A composição química das fezes dos animais alimentados com diferentes cultivares de palma forrageira (Tabela 4) reflete a composição da dieta ofertada. A porcentagem de matéria seca das fezes dos animais que receberam os cultivares redonda e miúda foram superiores à observada nas fezes dos animais que receberam cv. gigante. Entretanto, visualmente não foi observada diferença na consistência das fezes, além de não ter ocorrido diarréia, o que indica que o nível de fibra ofertado foi próximo ao recomendado como ideal para a o bom funcionamento do intestino e formação do bolo fecal. Os valores de proteína das fezes, independente do cultivar, foram superiores aos observados na dieta e também estão associados às perdas endógenas desse nutriente. A quantidade de cálcio e fósforo nas fezes foi elevada, o que tem relação com a quantidade ingerida desses nutrientes pelo sal mineral ofertado.

Tabela 3 - Leite produzido, relação entre produção de leite e matéria seca consumida e porcentagem de gordura, densidade e extrato seco do leite de vacas alimentadas com diferentes cultivares de palma, Arcoverde-PE

Table 3 - Milk prodution, relation between milk production and dry matter intake and percentage of milk fat, milk density and dry extract of cows fed different cultivars of cactaceae, Arcoverde-PE

\begin{tabular}{|c|c|c|c|c|}
\hline \multirow[t]{2}{*}{$\begin{array}{l}\text { Variáveis } \\
\text { Variables }\end{array}$} & \multicolumn{3}{|c|}{$\begin{array}{l}\text { Cultivares de palma } \\
\text { Cultivars of cactaceae }\end{array}$} & \multirow[b]{2}{*}{$\begin{array}{l}\text { Média } \\
\text { Mean }\end{array}$} \\
\hline & Redonda & Gigante & Miúda & \\
\hline $\begin{array}{l}\text { Leite produzido }(\mathrm{kg} / \mathrm{dia}) \\
\text { Milk prodution }(\mathrm{kg} / \text { day })\end{array}$ & $7,00^{\mathrm{a}}$ & $7,10^{\mathrm{a}}$ & $7,20^{\mathrm{a}}$ & 7,10 \\
\hline $\begin{array}{l}\text { Leite a } 4 \% \text { de gordura }(\mathrm{kg} / \mathrm{dia}) \\
4 \% \text { fat corrected milk }(\mathrm{kg} / \text { day })\end{array}$ & $7,36^{\mathrm{a}}$ & $6,92^{\mathrm{a}}$ & $7,65^{\mathrm{a}}$ & 7,10 \\
\hline $\begin{array}{l}\mathrm{kg} \text { MS consumida } / \mathrm{kg} \text { leite produzido } \\
\text { kg DM intake/kg milk produzided }\end{array}$ & $1,39^{\mathrm{a}}$ & $1,36^{\mathrm{a}}$ & $1,38^{\mathrm{a}}$ & 1,37 \\
\hline $\begin{array}{l}\text { Gordura }(\%) \\
\text { Fat }\end{array}$ & $4,15^{\mathrm{ab}}$ & $3,94^{\mathrm{b}}$ & $4,23^{\mathrm{a}}$ & 4,10 \\
\hline $\begin{array}{l}\text { Densidade do leite }\left(\mathrm{g} / \mathrm{cm}^{3}\right) \\
\text { Density }\end{array}$ & $1,03^{\mathrm{a}}$ & $1,03^{\mathrm{a}}$ & $1,06^{\mathrm{a}}$ & 1,03 \\
\hline $\begin{array}{l}\text { Extrato seco do leite }(\%) \\
\text { Dry extract of milk }\end{array}$ & $12,23^{\mathrm{a}}$ & $11,88^{\mathrm{a}}$ & $12,54^{\mathrm{a}}$ & 12,21 \\
\hline
\end{tabular}

Médias seguidas da mesma letra, na linha, não diferem pelo teste Tukey, a 5\% de probabilidade.

Means, within a row, followed by same letter, do not differ $(P<.05)$ by Tukey test. 
Tabela 4 - Composição química das fezes dos animais alimentados com diferentes cultivares de palma forrageira Table 4 - Chemical composition of feces of cows fed cactaceae cultivars

\begin{tabular}{|c|c|c|c|c|}
\hline \multirow[t]{2}{*}{$\begin{array}{l}\text { Alimento } \\
\text { Feed }\end{array}$} & $\%$ & \multicolumn{3}{|c|}{$\begin{array}{l}\text { \% Matéria seca } \\
\% \text { Dry matter }\end{array}$} \\
\hline & $\begin{array}{c}\text { Matéria seca } \\
\text { Dry matter }\end{array}$ & $\begin{array}{c}\text { Proteína bruta } \\
\text { Crude protein }\end{array}$ & $\begin{array}{l}\text { Cálcio } \\
\text { Calcium }\end{array}$ & $\begin{array}{c}\text { Fósforo } \\
\text { Phosphorus }\end{array}$ \\
\hline $\begin{array}{l}\text { Palma cv. Redonda } \\
\text { Cactaceae cv. Redonda } \\
\text { Palma cv. Gigante }\end{array}$ & $12,32^{\mathrm{ab}}$ & $10,27^{\mathrm{a}}$ & $5,56^{\mathrm{a}}$ & $0,38^{\mathrm{a}}$ \\
\hline $\begin{array}{l}\text { Cactaceae cv. Gigante } \\
\text { Palma cv. Miúda }\end{array}$ & $11,80^{\mathrm{b}}$ & $10,99^{\mathrm{a}}$ & $5,37^{\mathrm{a}}$ & $0,46^{\mathrm{a}}$ \\
\hline Cactaceae cv Miúda & $14,54^{\mathrm{a}}$ & $10,76^{\mathrm{a}}$ & $7,18^{\mathrm{a}}$ & $0,54^{\mathrm{a}}$ \\
\hline
\end{tabular}

Médias seguidas da mesma letra, na coluna, não diferem pelo teste Tukey, a $5 \%$ de probabilidade.

Means, within a row, followed by same letter, do not differ $(P<.05)$ by Tukey test.

O coeficiente de variação para as variáveis estudadas variou de 4,20 a $16,37 \%$, estando dentro do limite esperado para experimentos realizados em condições de campo.

\section{Conclusões}

Os cultivares de palma não diferiram quanto ao consumo in natura, quando fornecidas em associação com silagem de milho.

Os cultivares de palma não diferiram quanto à produção de leite de vacas $5 / 8$ holando/zebu.

\section{Referências Bibliográficas}

CHAGAS, A.J.C. Adoção de tecnologia na pecuária pernambucana. In: SIMPÓSIO NORDESTINO DE ALIMENTAÇÃO DE RUMINANTES, 4, 1992. Recife, PE. Anais... Recife: [s.n.], 1992. p.108-116.

COELHO, D.T., ROCHA, J.A.A. 1991. Práticas de processamento de produtos de origem animal. Viçosa, MG: UFV. 58p.

COSTA, B.M., MENDONÇA, C.A.G., CALAZANS, J.A.M. 1973. Forrageiras arbóreas e suculentas para formação de pastagens. Cruz das Almas: IPEAL. 24 p. (IPEAL. Circular, 34).

CUNHA, M.G.G. Efeito da adição de fibra em dietas à base de palma forrageira (Opuntiaficus indica Mill) sobre os parâmetros dafermentação ruminal e da digestibilidade em ovinos. Recife: UFRPE, 1996. 70p. Dissertação (Mestrado em Zootecnia) Universidade Federal Rural de Pernambuco, 1996.

FARIAS, I., LIRA, M.A., SANTOS, D.C., FERNANDES, A.P.M. et al. 1989. Efeito da frequência e intensidade de cortes em diferentes espaçamentos na cultura da palma forrageira (Opuntia ficus indica Mill), em consórcio com sorgo granífero (Sorghum bicolor (L.) Moench). Pesq. Agropec. Pernamb., 6(especial):169-183.

GERMANO, R.H., BARBOSA, H.P., COSTA, R.G. et al. Avaliação da composiçào química e mineral de seis cactáceas do semiárido paraibano. In: REUNIÃO ANUAL DA SOCIEDADE BRASILEIRA DE ZOOTECNIA, 28, 1991. João Pessoa, PB. Anais... João Pessoa: SBZ, 1991. p.3.

LIMA, M.A., FRANÇA, M.P., DIAS, F.M. et al. Emprego da associação palma forrageira e silagem de sorgo na alimentação de vacas Holandesas em lactação. In: REUNIÃO ANUAL DA
SOCIEDADE BRASILEIRA DE ZOOTECNIA, 22, 1985. Camboriu, SC. Anais... Camburiu: SBZ, 1985. p.133.

MATTOS, L, M. E. Associação da palma forrageira (Opuntia ficus indica Milll) com diferentes fontes de fibra, na alimentação de vacas mestiças em lactação. Recife: UFRPE, 2000. 51p. Dissertação (Mestrado em Zootecnia) - Universidade Federal Rural de Pernambuco, 2000.

MATTER, H.B. 1986. The utilization of opuntia for nutrition of livestock. Anim. Res. Devel., 23: 23-107.

MERTENS, D. R. Análise da fibra e sua utilização na avaliação de alimentos e formulação de rações. In: REUNIÃO ANUAL DA SOCIEDADE BRASILEIRA DE ZOOTECNIA. Anais...Lavras: SBZ, 1992

NUTRIENT RESEARCH COUNCIL - NRC. 1988. Requeriments of the dairy cattle.6.ed.Washington, DC., s.ed. 157p.

PROPI, D.P., McLENNAN, S.R. 1995. Protein and energy utilization by ruminants at pasture. J. Anim. Sci., 73:278-290.

SANTANA, O.P., VIANA, S.P., FARIAS, I. 1972. Palma versus silagem na alimentação de vacas leiteiras. $R$. Soc.Bras.Zootec., 1(1):31-40.

SANTOS, D.C., FARIAS, I., LIRA, M.A. et al. 1997. A palma forrageira (Opuntia ficus-indica, Mill. e Nopalea cochenillifera, Salm Dyck) em Pernambuco: cultivo e utilização. Recife:IPA, 23p. (IPA. Documentos, 25).

SANTOS, M.V.F., LIRA, M.A., FARIAS, I. et al. 1990. Estudo comparativo das cultivares de palma forrageira gigante redonda (Opuntia ficus indica Mill.) e miúda (Nopalea cochenillifera Salm-Dyck.) na produção de leite. R. Soc.Bras.Zootec., 19(6):504-511.

SANTOS, M.V.F., LIRA, M.A., FARIAS, I. et al. 1992. Efeito do período de armazenamento pós-colheita sobre o teor de matéria seca e composição química das palmas forrageiras. Pesq. Agropec. Bras., 27(6):777-783.

SANTOS, M.V.F., FARIAS, I., LIRA, M.A. et al. 1998. Colheita da palma forrageira (Opuntia ficus indica Mill.) cv. gigante sobre o desempenho de vacas em lactação. R. Soc. Bras. Zootec., 27(1):33-39.

SILVA, D.J. 1990. Análise de alimentos: métodos químicos e biológicos. Viçosa, MG: UFV. 166p.

VAN SOEST, P.J. 1994. Nutritional ecology of the ruminant. 2.ed. Cornell: Cornell University Press. 476p.

Recebido em: 08/06/00

Aceito em: 14/08/00 